\title{
The Dynamics of Directing for the Stage and the Screen
}

\section{*Yinka Smart BABALOLA}

\begin{abstract}
Using historical-analytic method, this article examines the dynamics of directing for the stage and the screen. It argues that even though the process of directing is a tough one both on the stage and the screen, it can be very interesting and rewarding for the strong-willed, creative director (artist). It further posits that contemporary theatre is so sophisticated and highly technologically driven that a stage director must of necessity be artistically and technically savvy to be effective in play production in the theatre. As creative and interpretive artists, post-modern, multicultural and globalized directors constantly seek new means of creative exploration through a shared experience of experiments in multimedia, visual arts and cultural expressions of the performance theatrical traditions existing all over the world. This is the key link in the works of creative high concept directors such as Jerzy Grotowski, Peter Brook, Eugenio Barba, Robert Lepage, Simon Mcburney, Lev Dodin, Elizabeth LeCompte and those of textinterpreters and author-centred directors such as Max StaffordClark, Katie Mitchell and Declan Donnellan. Contemporary directors are seeking new ways of developing strong óphysically embodied theatreôand must continuously strive to work across the theatre/film/television divides, and feel be at home in the different media to bring their visions to bear on creative works beyond the confines of any single medium for the gratification of the ever óungryôaudience.
\end{abstract}

Keywords: Directing, Stage, Screen, Multimedia, Contemporary directors, Theatrical traditions

\section{Introduction}

Directing as an art is very difficult to define. This is because most

*Yinka Smart BABALOLA of the Department of Theatre Arts

University of Ibadan, Ibadan Email: yinkasmart1@ gmail.com 
definitions fail to capture the full essence of the art and craft as it applies to the stage and the screen. For instance, directing is conceived by Beck et al (quoted in Umukoro, 2002) as the controlling force for unifying all facets of the production of a play. Many scholars, such as Dean and Carra (1980); Umukoro (2002); Brocket and Ball (2004); Felner and Orenstein (2006); and Felner (2013), regard directing as the art of coordinating all the activities that ultimately lead to the production of a play, and a director as that superhuman who provides a unified artistic interpretation of a particular play for a particular audience. Felner and Orenstein observe that the art of directing ñies in making decisions about how to use all the means available to create a compelling theatrical encounterò (2006). All these definitions have considered just one aspect of the art of directing, which is play production for the stage.

Directing as an art exists beyond the confines of the theatre and beyond play production. Apart from the theatre, directing exists in live performance arts/events, radio, television and film. Directing also exists at different levels, even within the same medium. For instance, in film and television, different programmes have different types of directors. News, music, drama, animation, children, variety show, commercials, reality TV, etc., programmes have directors who possess different specialized skills needed for the different media. As directors, however, they are driven by a common purpose - pursuing the ultimate concept and vision for the production. Irrespective of the medium, directing makes rigorous demands on the directorôs natural and acquired abilities, especially in the area of artistic and technical requirements. Therefore, directing as an art can be summed up as the process of coordinating all the human, technological, artistic and sometimes financial elements of a production, be it in theatre, mass media or performance arts/events.

The art of directing, which was born on stage, is relatively one of the youngest but perhaps the most demanding of all the arts of the theatre. Dean and Carra (1980) claim that the nearest counterpart to directing in western dramatic production history is the Choregus in the Greek dramatic festivals, who was a business 
manager and also trained the chorus, although many theatre historians such as Wickham Glynne (1992) and Brocket and Hildy (2010) believe that the playwright in the Greek theatre trained the chorus and superintended rehearsals. In any case, Felner and Orenstein (2006) assert rightly that these roles, including those of the Roman theatreôs actor-managers, Medieval theatreố pageant masters, Elizabethan theatreôs leading men, etc., were organizational roles rather than ñvisionary or interpretive onesò. With other theatrical traditions outside the West, directing as art in itself did not exist until the contemporary times when artistic directors are employed to coordinate festivals, carnivals, among others. In performance theatrical traditions across Africa, Asia and Latin America, the lead performers, who are often chief priests or narrators, are usually responsible for training the neophytes and coordinating the total performance in line with laid down conventions of the specific performance. This is evident in Japanese Kabuki theatre, Indian Khatakali and African festival theatres such as Egungun or New Yam festivals where the conventions of visual and aural aesthetics are strictly adhered to by generations of performers.

The modern director, as we know it today, came into being during the late eighteenth century in Europe. This birth is traceable to the rise in experiments towards a unified production, the movement in the direction of realism and interest in scientific exploration of cause and effect in the dramas of Henrik Ibsen and other pioneers of realism. Several theatre and artistic figures of the time contributed immensely to the evolution of the art of directing and in shaping the role of the modern director. Notable names whose consistent works and experiments paved way for the art of directing include Johann Wolfgang von Goethe (1749-1832), Georg II, The Duke of Saxe-Meiningen (1826-1914), Richard Wagner (1813-1883), Andre Antoine (1858-1943), Constantin Stanislavski (1863 1938) and Erwin Piscator (1893-1966). The new movement in realism/naturalism expressed in the plays of Emile Zola (1840-1902), Henrik Ibsen (1828-1906), August Strindberg (1849-1912) and Anton Chekhov (1860-1904) with ñpsychologically complex characters who grew out of particular 
social millieusò (Felner, 2013:188-90), created the need for specific stage setting particular to each play as opposed to the generic visual conventions of the past and ñthe need for an artistic eyeò to unify the stage elements with the play text, demanded the conception of the art of directing. Stanislavskiôs work at this period has remained one of the most enduring contributions to the art of directing in the theatre due to its integrated actor training and the realistic stagecraft. According to Felner and Orenstein, ñthe modern director as visionary, unifier, and guide to actors was born in Stanislavskiôs early workò (2006). In this period, the theatre was the sole medium of artistic expression and mass entertainment; hence, the director existed only in the theatre until the birth of film, radio, television, video and the internet.

Today, the role of a director is far more complex and demands multi-skills and multimedia, unlike in the late $19^{\text {th }}$ and early $20^{\text {th }}$ centuries. A director can traverse different media, depending on the ability to acquire specialized skills and technical abilities needed for the different media. Directors like Elia Kazan (1909-2003), Lloyd Richards (1919-2006) and Michael Mayer (born 1960) are known to have successfully directed productions for the stage, film and television. A director willing enough can be trained in the different areas and media and can ply his or her art in any of the areas as well. But directing is a very complex and taxing art to the extent that many directors would rather stay in one area of specialization such as film, television or theatre. A director requires many years of training and practice to become highly skilled and confident. Therefore, very few people opt for directing as a specialism. For the interested, directing skills for the stage can be acquired in theatre/drama schools or universities with theatre/performing arts departments. Film/television directing skills can be acquired in film/television schools. Also, directing skills can be acquired by apprenticeship, even though this is becoming less attractive because of scarcity of mentees and mentors and, of course, many believe that apprenticeship has become a ñconditioning force that deeply discourages self-evaluation and changeò(Rabiger 1997). 


\section{The Fundamentals of Stage Directing}

Stage directing is primarily concerned with the following: script interpretation/performance creation; understanding the performance environment; understanding visual and aural aesthetics; and working with performers, designers and technicians. A stage director is primarily an interpretive artist with a keen sense of obligation to the playwright and his or her own audience. Umukoro asserts that the directorôs interpretation of the text is a crucial function which must be properly handled because his/her interpretation ñbecomes the interpretation of the groupò. Therefore, it is very important that the director recognizes the ñplaywright as the initial creative forceò (2002). The reality of this statement is that the director must be versed in dramatic literature and be adept in reading and research generally in order to be able to do justice to a dramatic piece during interpretation. It is from reading and re-reading that the director builds up, in his/her mind, the imagined physical and psychological environments for the production which he or she eventually physicalizes on stage. Stage directors direct much the same way every time, thereby stamping their own techniques and personalities on productions which in time become discernible styles in their works. However, it is very important that directors be versatile because all plays are not the same, hence, interpretation cannot be approached in the same way every time. Dean and Carra suggest that directors should approach interpretation from both the auditory and visual imagination, rather than from just one of both. This will lead the director to fittingly harmonize his or her production in concept, mood, style, genre and stagecraft (1980).

Some directors are creative artists who create performance from an idea or something new from existing works of art. Such directors are known as director-auteur. These are artists who adapt plays freely to serve their own purposes and create their own production texts. According to Felner and Orenstein, directorauteurs exercise considerable ñcontrol and authority over all aspects of the production, and performance is the realization of a complete and personal visionò (2006). The works of Richard Foreman (born 1937), Lee Breuer (born 1937) and Mary 
Zimmerman (born 1960) in the United States of America (USA) have reinforced the idea of the director-auteur seizing the freedom and control over artistic vision. This concept should not be confused with the idea of a playwright, such as Femi Osofisan, directing his own work which can also be realized by others. For auteurs, the ćconceptô is part of the text which cannot be easily reproduced by others (Felner, 2013). Makbutu, which was devised by Chuck Mike and the Performance Studio Workshop in Lagos in the 1990s, is a reconceptualization of Shakespeareôs Macbeth and a classic Nigerian example of performance text evolving from a director-auteurôs creation. Over a decade after this production, the performance text, Makbutu was re-adapted and re-conceptualized by another creative director, Tunde Awosanmi, in Ibadan into an artistic and cultural compendium to question the African despotic leadersôunbridled ambition and unquenchable thirst for blood.

The stage director, as a matter of importance, must fully understand his or her physical, intellectual, psychological and spiritual performance environment. This is in order that he/she can best locate his production within the context of his audienceôs worldview and their psycho-social understanding. The director strives to provide the audience with a deeper understanding of the play text in his work using all the technical and artistic elements at his disposal. Therefore, the audience must be located in an environment that can enhance their understanding and foster enjoyment of the performance. For instance, a play showing to mass audience cannot be overtly intellectual and artistically interstellar. The audience may lose all the essence of the performance. The director therefore, creates his or her actions within the limits of his/her audiencesô understanding and the conventions of his/her performance environments.

Understanding staging conventions is, therefore, crucial to play interpretation. Once a director decides on a particular staging concept and production style, he or she observes the conventions of that style because each style and concept demands particular physical realization. Hence, a drama set in proscenium, thrust or arena stage follows the conventions of these stages. So also is a play stylistically conceived by the director for staging either in 
realism, symbolism, epic, absurd or environmental concept must necessarily follow the conventions of the concept so that the audience can follow a clear conceptual path to understanding the production. Where a director decides to experiment with stylistic eclecticism, he or she must understand the basic tenets of all the styles and be clear on the reason for his or her decision and the intellectual ability of the audience, for plays are made for the audience enjoyment not to confuse them. Furthermore, the stage director must be conversant with the fundamental tools of stage directing. These are the tools that the stage director uses to physicalize his or her concept and bring a play text to life. Writers and experts have categorized these in many different ways, but for the sake of simplicity, this article categorizes these into visual and aural aesthetics. The visual aesthetics is what Dean and Carra (1980) term the ñfundamentals of play directingò These are composition, picturization, movement, rhythm and pantomimic dramatization. The aural aesthetics are speech and oratorical art, sound and sound effect, music and song. Basically, the tools that affect what we see and what we hear when we watch a play.

Composition is the environmental structure of the stage; the form and design of the set elements and people on stage. In film this is referred to as ómise-en-sceneô(Eregare and Omoera, 2008). The totality of what is seen on stage. Composition does not convey the meaning of the picture but expresses feeling, quality and mood of the dramatic situation through the design elements of colour, line, mass and form. In directing, elements of composition such as order, emphasis, balance and sequence, are used to realise clarity and beauty (Dean and Carra, 1980). A director should understand the principles of arranging people and set pieces on stage to achieve his or her artistic goals. Picturization on the other hand, is the visual interpretation of each moment in a play and the ordering of characters within a setting that reveals to the audience the mental and emotional attitudes through their physical interactions without the need for dialogue or even movement. This visual image helps the audience to understand the inner sub-textual meanings of the play (Dean and Carra, 1980). 
The bulk of a directorôs visible work is seen in the ólockingsôhe or she gives to his or her actors. Blockings contain a sequence of movement, pantomime and stage business given by directors to enhance ñcharacter evaluation, emphasis, variety and mood expressionò Movement is the constantly changing stage picture which has in itself a ñdefinite picturizing valueò (Dean and Carra, 1980). Generally, movement can be described as the shifting of a part or the whole body (mass) in time and space. The minutest shifting of a body part, such as blinking or breathing, constitutes movement. Movement is in two broad categories - locomotor and non-locomotor. While locomotor is the kind of movement that gets the performer from one spot to another, non-locomotor is that movement of the body that does not shift the whole body from one place to another. Thus a walk, jump or leap is a locomotor movement, while the wave of an arm, bending or swaying is nonlocomotor. These forms of movement are not usually executed independently or exclusively and they aid the flow and dictate the rhythm and mood of the play. Rhythm, as one of the fundamental aesthetics of directing, is not easily describable but it is always experienced in stage performances. It is ñthe experience of a sequence of impressions, auditory and visualò, ordered into ñecurrence of accented groupsò. Rhythm is a regularly recurring accent in a play and it varies in tempo and pattern according to changes in emotional, physical or mental impulses (Dean and Carra, 1980). Thus a play is expected to follow a set rhythmic pattern - tempo, time and pace - of the different beats and scenes in consonance with the dramatic situations contained in them. It is the work of the director to unearth the visual and auditory rhythm of the production buried in a play text.

Directors also work with actors to produce a complete visual performance of a play, which if devoid of dialogue, still conveys meaning. This complete visual performance includes the use of composition, picturization, movement, rhythm and pantomime. Pantomime, according to Dean and Carra (1980), is the sequence of facial expressions, gestures, hand and body positions and movements used imaginatively by the actor to reveal the character, situation, locale and atmosphere of a play. 
Pantomimic dramatization, therefore, is the combination of all of the above, including stage business, to achieve meaning in a play without the use of words (Dean and Carra, 1980). Visual aesthetics are important to the director just as aural aesthetics in play directing. Aural or auditory aesthetics is composed of all that is heard and how it is heard in a performance. Hence, speech and oratorical arts, music, songs and sounds of the world of the play all aid the audienceôs understanding of the mood, style, locale, relationships and emotional conditions of the play. They also set the playôs rhythm and tempo and unveil the plot and the story. The actor needs to pay ñproper and conscious attentionò to speech for effective communication in all its different stages and forms, including the ñmanipulation of certain physical organs of articulationò (Benson, 2010). Therefore, a good director needs to understand that human communication is not only non-verbal but also verbal, and stage communication is both visual and auditory. Hence, careful attention must be paid to aural aesthetics as with visual aesthetics during rehearsals and in the final preparations for the production.

These visual and aural aesthetics are key elements a director must consider and choose carefully in directing a play. Therefore, a serious director takes it upon himself to understand all the artistic tools of directing and how to apply them in different circumstances in different plays. When they are well understood and properly employed, these elements aid the understanding of the intellectual and emotional world of the dramatic situation. Dean and Carra emphasize that these constitute the note scale of play directing and are the means by which a ñdirector may express the emotional and intellectual qualities of a playò (1980). Working with other creative artistes during play production is another important aspect of directing. A good grasp of the fundamental aesthetics mentioned above is no substitute for a directorôs interest in honing of his managerial, communication, interpersonal and leadership skills in order to work successfully with others in a creative environment. Therefore, a directorôs ability to create a fertile creative environment and forge a good working relationship with actors, designers, technicians, artisans and business personnel 
is vital to his work. Since it is a creative endeavor, the director needs to allow an unimpeded flow of creative juice from his actors, designers and technical personnel. With a clearly communicated concept, everyone must be allowed to apply his expert knowledge and skill to the overall development of the work. The director stands as a master planner, directing these creative energies towards a desired end.

Although there are directors who also serve as their own designers, such as American director, Robert Wilson (born 1941) and Nigerian director, Sumbo Marinho (1942-2010), most directors work with designers in the tedious process of production designs; meeting severally at the pre-rehearsal stages to discuss the play and the production concept. This is to achieve a unity of purpose. However, as Brocket and Ball opine, from the approval of the concept to the final rehearsal, the director and the designer more or less work independently (2004). While the director is busy with rehearsals and working with actors, the designer is busy with sketches and models, seeing the director only when he has something to discuss or show to him. One of the most important roles of the director is working with actors. After selecting his cast, either by audition, invitation or by a collaborative design, the director immediately begins working with his actors either in full or pocket rehearsals, bringing out his vision of the character from them through script interpretation, blockings and integrated mental, physical and vocal exercises. Where necessary, the director trains up his actors to achieve specific styles or concepts. At the directorôs disposal are varied acting techniques to choose from in the training of his actors. These include Stanislavskiôs Method of Physical Action, Meyerholdôs Biomechanics Technique, Grotowskiôs Poor Theatre, Stella Adlerôs Imaginative Technique, Meisnerôs Technique and the Michael Chekov Method. Finally, the director supervises rehearsals and the process of physicalizing the concept, ñbut a director is not a dictatorò. He allows actors to contribute their own artistic visions in a free atmosphere while he makes suggestions for improvement during rehearsals. Effective directors, according to Brocket and Ball, are ñusually sensitive 
listeners, observers, critics, disciplinarians, teachers, and friendsò (2004).

\section{The Aesthetics of Screen Directing}

Screen directing methods are the same for film, television and video, though the scale of operations and the paths to completion may be different (Rabiger, 1997). All the identified types of filmmaking also exist in Video and Television. The objective and the audience may be different, but the methods are alike. The most important aspect of screen directing is individuality and subjectivity. Ralph and Debrix acknowledge this when they assert that how a film director shows an object depends primarily on the dramatic action or the type of film being made or on the primary audience: ñAn operation will be filmed in one way for an audience of medical students and in another way for a general audience in an entertainment filmò (1968). The techniques applied by directors in film in terms of dramatic action, strengthen the understanding of such films. For instance, John Huston (1906-1987), the director of Key Largo (1948) and Freud (1962), among many others, in placing and moving his characters within a shot is nearly always concerned with simplicity and spontaneity, rather than merely by dramatic or visual effectiveness. His pictures have a visual tone and style of their own, dictated to his camera by the storyôs essential content and spirit (Agee, 1969). Technically, it is possible to procure a story and assemble cinematographers, actors, production designers and editors and, without a director, and following the screenplay, record the story on film or video. r̃ But without the guidance, leadership, and vision of a central figure, it will never be more than just thatठ a story recorded on film or videoò. It takes a director to visualize a good story and turn it into ñmotion picture with intention and purposeò(LoBrutto, 2002).

\section{Vision}

The birth of film art led not only to the creation of new works of art but to the emergence of new human faculties with which to perceive and understand this new art. The screen director must learn the technique of the film camera which has produced a new 
way of presentation and a new language for telling story different from the theatre. The film language essentially rests on the field of view, the angle of view, camera movement and mode of transition. These form the properties of the image that speak to the audience. On screen, therefore, the composition of images rests on the field of view. This describes the area seen by the camera. In this context, according to Ekwuazi (1990), there are three units of shots. The long shot (LS) is the first unit which could be divided into three via the extreme long shot (ELS), the long shot (LS) and the medium long shot (MLS). The second unit is the medium shot consisting of the medium shot (MS) and the medium close up (MCU). The last unit is the close ups. This comprises the close up (CU), the extreme close up (ECU) or the tight close up (TCU). The screen director must be fully conversant with the different shots, their uses and manipulation to enhance creative storytelling.

The camera angle or angle of view is an important aspect of filmmaking that is basically used to express subjectively what the objects are like as seen through the eye of the camera or a character in a film. The angle is of three kinds: the eye level, the low angle and the high angle. The eye level angle is the normal angle. This is ordinarily the angle we view life. In Hollywood, this is usually between four to six feet. But the Japanese have a lower eye level because of their life-style. The low angle and the high angle are both exaggerated angles. The low angles make the subject larger while the high angle diminishes the subject in size. These exaggerated camera angles are for dramatic effects and creative subjective shots. Hitchcock shows the movie value of the special tones and looks of people with special backgrounds at special jobs, through camera angle. In his film Psycho, high and low angle shots of Lila and the house were intercut to create a frighly suspenseful sceneò that appears ñeven more frightening by implying that the high-angle might be the POV of an unseen characterò (Sijll, 2005).

Camera movement is another vital aspect of vision in film. There are two kinds of camera movement: the non-spatial or axial and the spatial movements. The non-spatial movement consists of the pan, the tilt, the pedestal and the zoom. Spatial movement comprises the crane, the trucking and the dolly. Non-spatially, on 
the $90^{\circ}$ axis, the camera tilts up or down. While on the $360^{\circ}$ axis, it pans left or right. Raising and lowering the pedestal, a camera mount peds up and peds down. The zoom creates the effect of movement, of the camera moving in or out on the action. It is the movement of focal lenses. The crane shot gives an aerial view of the action. The trucking is a mobile camera mount. Whether the camera trucks left or right, the movement must remain parallel to the action/subject. The dolly, however, is a camera mount that is movable. This allows the camera to move towards (dolly in) or away (dolly out) from the action. The dolly is often used in horror films because it is more effective than the zoom. It should be noted that with the use of the Steadicam camera support, spatial and nonspatial movement can easily be combined within the same take.

The factors necessary for effective image composition rests on the proper usage of camera movement. Camera movement starts from keeping a moving subject in sight, highlighting the temporal relationship among subjects as well as establishing spatial relationships. It could be used also to impart the illusion of movement to static objects. It also enhances the idiom of point of view, creation of the illusion of three dimensionality on twodimensional frame and annuls the limitations inherent in the fixed and static proportions of the frame (Ekwuazi 1990). The screen director needs to know that camera movement calls for the understanding of the relationship between the action/subject and the camera. It is also a self-conscious technique that should be dramatically and technically motivated to achieve an artistic image composition. Many directors, especially theatre-trained ones, shoot dramatic action in the way a photographer records a stage performance, replacing creative camera work and cinematic storytelling with tardy, long dialogues and theatricalised acting of the stage. This is sadly the case with most Nigerian video-films. Hitchcock laments this unfortunate practice: ñé with the arrival of sound, the motion picture, and overnight, assumed a theatrical form. The mobility of the camera does not alter this facté ò (Sijll, 2005). 


\section{Motion}

What we see on the screen is a photograph. That is, it was created on the screen as a painting is created on canvas, but was already previously existent and visible in reality. It had to be enacted in front of the camera; otherwise it could not have been photographed. This implies that actual artistic creation is performed in the studio or on location before the camera in space and the shooting in time. Everything had first to be reality before it could become a picture. Hence, the film we see on the screen is merely a photographic reproduction. As Pincus puts it; ñfilm is made up of series of still photographs, each of which shows slight change in motion when projected, they give the illusion of a moving image. That is, the eye amalgamates the many images into a continuous moving imageò (1972). This phenomenon is aptly known as ñpersistence of visionò Each of these still photographs is called a frame. In silent film, the exposure and projection of these frames is at 18 frames per-second, while sound film is usually exposed and projected at 24 frames per-second (FPS). When the camera runs at a higher speed than normal, the effect is slow motion. Any speed below 24 FPS in sound film will give fast motion effect. In the earlier days, fast motion was a widely used style of achieving comic effect in slapstick comedies of Charlie Chaplin, Mack Senneth, Max Linder, Harold Lloyd and Buster Keaton. The effect produced by accelerated motion is both funny and it enhances brilliance of the action which the films project. In adventures as well as action-packed thrillers, fast motion has been found effective in aiding the action and intensifying excitement.

The slow motion is used for mood creation as regards dreams and fantasy as well as tragic situations. Reverse motion is rather rare but has been artistically put to use in various films. It is rather eccentric in form and in communication. It has been used in the earlier days for comic effect and for no serious reasons. Sergei Eisenstein (1898-1948), in October (Ten days that shook the World), produced in 1928, used reverse motion to show symbolically the restoration of the áncient regimeôi statue of the Tsar previously smashed to pieces. This becomes effective because of its symbolic use in the film which has to do with reconstruction 
of the critical days between February and October 1917, ending in the fall of the provisional government (Eisenstein, 1970). Stopped motion, is another film technique which is achieved by the đFreezingôof action of a moving sequence as well as the use of still photographs. George Melies (1861-1938) developed this technique by exposing one frame at a time. The camera is rolled for each exposure. The camera could be stopped at any point to accommodate any change in action or effect before it is rolled again. This technique creates the illusion of appearance and disappearance in Hubert Ogunde and Moses Adejumo films. In Jaiyesimi, Ogunde made Oseitura, the chief priest, disappear and re-appear. Ogunde uses this technique to enhance the magical concept of the film. What the audience sees is an all-powerful, mystical and magical Oseitura. In motion, speed, as seen in fast motion, slow motion, stop motion and reverse motion creates the aesthetically pleasing event that is real to the audience.

\section{Sound}

Next to sight is hearing: The richest and most complex of our senses. Sound is the basis of music, which is one of the greatest of the arts. As speech forms a medium of thought and is the most important means of communication among human beings (Ralph and Debrix, 1968:30). Motion pictures and sound were conceived as working together in principle from the very beginning. Films were not silent because people wanted them to be; they were always a compromise necessitated by a lack of technological skill and knowledge. The advent of sound in motion picture increased the reality of the image and the action. To some earlier directors, sound had destroyed something unique and placed severe limitations on the state of the art. But they saw that there was a positive side to be developed. In the early days, there was the lack of creative use of what sound could exquisitely contribute to film, coupled with a restoration of the artistic visual potential of camera movement and editing. Artificial sound is now used through advanced technology by filmmakers to multiply, intensify and transform sounds through orchestration and perception. 
Also, artificial distortion of sound to gain special effects is developed. Sound can also be employed in some other ways in films. For instance, many natural sounds we hear from the speakers at a cinema are blended after the shots have been taken. This is direct blending of sound to make the audience identify with the world of the film; the background and setting (Balasz, 1970). Early sound movie directors like Reuben Mamoulian (Silk Stokings, and Applause) and King Vidor (The Crowd) make an extensive use of sound stylistically. In Mamoulianôs Can-Can, for example, the sound of a typewriter is juxtaposed with the typist of a boss typing out punishment of the three men standing in front of her. Instead of using the natural typewriter sound, which would be undramatic, Momoulian employs a deafening ominous sound, like the one a drill boring into concrete makes. This sound symbolizes the emotional state of the three men as they wait for the letter containing the punishment to be handed to them soon. Of course, the sound is not realistic, but the mental picture it creates awakens the audienceôs imagination to the scene. Closely allied to the use of natural sound in film to denote setting and action, is the sound used for emphasis, feelings of suspense, fright, horror, excitement, which conveys the mood and tempo or rhythm of a scene in film. Sound has become so effective that it aids every form of feeling or meaning a director wishes to convey through its naturalistic as well as stylized usage on the screen (Foluso, 1987)

\section{Montage and Editing}

Perhaps the most important concern of the film director is editing. Editing is the selecting, cutting and arranging of shots into sequences, and of sequences into a movie. A director armed with a script goes into shooting without much thought for sequence because it is not the script that determines the order of shots but technical convenience. Even if a film is taken in the narrative sequence, the many takes and re-takes, cutaways and special effects such as animation created in the laboratory, will definitely make editing necessary. The film editor becomes significant at this point ñé cutting to create requisite rhythm and tempo, he releases a story that in rhythm, in style and in texture is different from what is 
enacted before the cameraò (Ekwuazi, 1984). Through the application of axis of action line, the eyeline match, the point of view shot, the match on action cut and directional continuity, editing techniques help to properly orientate the audience by placing the audience on the same side as the action, creating an impression of a coherent scenic space (Buckland, 2010). Editing plays an important role in the filmic medium. Bordwell and Thompson (1980) reiterate that editing creates and contracts as well as expands time and space. Also, it has impact on the work of the actor ñbecause after editing, the actorôs performance changes on screenò. The editor determines the interpretation of action in the way he cuts the film (Babalola 1990).

There are two basic kinds of editing: discontinuity and continuity editing. The discontinuity editing is identifiable with the Russian montage or formalist school, specifically, with Pudovkin and Eisenstein. This type of editing involves constructive editing, structural editing, rhythmic editing, tonal editing, over-tonal editing and intellectual or ideological editing. In continuity editing, there is only one rationale for the continuity editing system, and this is narrative continuity. Continuity editing of the Hollywood purists is of two kinds: Spatial continuity and temporal continuity editing. Montage, on the other hand, has been loosely employed in different contexts through film history. The early Russian directors used it as a synonym for áreative editingô while in France, it means simply cutting. The British and American studies refer to it as the ñquick impressionistic sequence of disconnected images, usually linked by dissolves, superimpositions or wipes, and used to convey passages of time, changes of place or any other scenes of transitionò (Reisz and Miller, 1968). When these shots are joined, or juxtaposed, the separate shots combine into a meaningful synthesis, an artificial whole. Montage, according to Buckland, ñdoes not attempt to construct a coherent scenic space, but to create a symbolic meaningò (2010). Montage and editing have become inseparable as well as inter-changeable in that montage is the heart of editing. They are fundamentally characterized by cutting from one shot to the next, thereby enhancing the continuity of space and time within a filmôs action. This is clearly shown in experiments 
carried out in the Soviet silent cinema and was sponsored by Kuleshov and his students, notably Pudovkin and Eisenstein. The most famous of these experiments was the one in which Mosjukhin, the Russian actor, shot neutral, static or quite close ups of him and these shots were intercut with other shots; first a bowl of soup, then a dead woman in a coffin, and finally a little girl at play.

The result was that the audience was immensely impressed by the fine acting of the artist (Pudovkin, 1958). These experiments were an exercise in creative geography and the celebration of the screen conquest of time and space. The radicality of Eisenstein as expressed in his films, full of what he called ñntellectual montage,ò is another cornerstone in film editing and montage. His films áderive their appeal from the manner in which he exposed certain ideas rather than from its excitement as a dramatic story like Griffith, or the psychological perceptibility of Pudovkin. For instance, in October, Eisenstein shot the incidents in a loosely constructed manner which does not follow each other with the dramatic inevitability of a good story. He wanted his films to produce momentary shock in their lack of smooth cuts, resulting in continuities full of collisions (Reisz and Miller, 1968). Pudovkinôs five principles of editing choices are still as relevant today as they were over a hundred years ago because they help in the ñpsychological guidanceò of the audience. These are Contrast (relating two contrasting shots/scenes for emphasis), Parallelism (where two thematically unconnected incidents are developed in parallel), Symbolism (introducing abstract concept into the consciousness of the audience), Simultaneity (simultaneous rapid development of two actions) and Leit-motif (emphasising the basic theme of a scenario) (quoted in Sijll, 2005). Therefore, on both the practical and intellectual levels, the film director must be conversant with editing tools and their applications as well as the subtleness of the art of editing in relation to his work as a director. Editing makes or mars a production and it is the directorôs ultimate duty to handle this post-production aspect of filmmaking with clarity of purpose and a full understanding of the principles and the 
work involved and how best to apply man and material resources to achieve his concept.

\section{Conclusion}

Directing is a vital art of the theatre and certainly that of the media. Though the process of directing is a tough one both on stage and screen, it can be very interesting and rewarding for the strongwilled. The contemporary theatre is so sophisticated and highly technologically driven that a stage director must of necessity be artistically and technically savvy to be effective in play production in the theatre. As creative and interpretive artists, post-modern, multicultural and globalized directors constantly seek new means of creative exploration through a shared experience of experiments and devising in multimedia, visual arts and cultural expressions of the performance theatrical traditions existing all over the world. This is the key link in the works of creative high concept directors such as Jerzy Grotowski, Peter Brook, Eugenio Barba, Robert Lepage, Simon Mcburney, Lev Dodin, Elizabeth LeCompte and those of text-interpreters and author-centred directors such as Max Stafford-Clark, Katie Mitchell and Declan Donnellan. Contemporary directors are seeking new ways of developing strong ñphysically embodied theatreò or of developing ñnew work by young playwrightsò (Shevtsova and Innes, 2009). Many directors, such as Michael Mayer, also work across the theatre/film/television divides, at home in the different media and bringing their vision to bear on creative works beyond the confines of any single medium.

Film as business has and is undergoing big changes due to profound changes in electronic technology. The computer and internet have changed the traditional notions and principles of filmmaking and distribution. This should be of serious interest to experienced and new filmmakers/directors because of the new possibilities and approaches to creative process the computer represents. From managing images and sound faster and converting these to digital codes, the electronic medium has certainly become an ñextraordinarily pliantò one in which ñanything that is created can be instantly alteredò (Katz, 1991). Computer technology has fully dominated the film business and 
almost all the equipment needed for production is computerized. Hence, contemporary directors must be well instructed and be conversant with this technology in order to be able to deliver creative vision with the limitless possibilities of computer technology. In addition to being well trained technically, a film director can only become outstanding by having or developing $\tilde{\mathrm{n}}$ strong artistic identityò because directing on screen, just like on stage, is bringing people of different skills together, and it is a ñlong and lonely struggle to keep going and hold on to (the) original visionò (Rabiger, 1997). This is why a director must be practice-led, confident, know his or her limits and lead his or her cast and crew with a perfect blend of humility and toughness.

In both the stage and the screen, the directorôs relationship with his actors is extremely important and it is the dynamics of this relationship that gives life to the character which propels the story. Therefore, the director works with actors in rehearsals in mutual trust, to assist the actor discover the perfect character through blockings, exercises and script interpretation (Rea and Irving, 1995). For the stage and the screen, the scale of the production has a direct relationship to the functions of a director. According to Kennedy, the director of a large scale production with a compliment of production staff is more able to concentrate on the job of directing better than that of a small scale production with limited staff. Such a director will have to multi-task as the sole creative force and execute many of the roles in order to have his creative vision fulfilled (1989). In any case, to be a consummate artist whether on stage or screen or both, a director must pay serious attention to training. The university, art and film schools offer formal avenues for training, just as apprenticeship and on-thejob training, as in the case of directors who have risen through the paths of acting, design or play/script writing. 


\section{References}

Agee, J. (1969). đ́ndirectable directorsôï Agee on film: essays and reviews by James Agee. Universal Library Edition. Vol. 1.

Babalola, Y.S. (1990). Film aesthetics: A conceptual analysis of Ladi Ladeboôs films. Unpublished B.A Project, Department of Theatre Arts, University of Ibadan.

Balazs, B. (1970). Theory of the film: Character and growth of a new art. New York: Dover Publication Inc.

Benson, A.A. (2010). Effective speech training for the theatre student-actor. Ibadan Journal of Theatre Arts 5\&6, 157165.

Bordwell, D. and Thompson, K. (1980). Film art. Massachusetts: Addison-Wesley publication Company.

Brockett, O. G. and Ball, R.J. (2004). The essential theatre. $8^{\text {th }}$ edition. Belmont: Wadsworth.

Brockett, O.G. and Hildy, F.J. (2010). History of the theatre. Boston: Pearson Education, Inc.

Buckland, W. (1998). Understanding film studies. London: Hodder Education.

Dean, A. and Carra, L. (1980). Fundamentals of play directing. New York: Holt, Rinehart and Winston.

Ekwuazi, H. (1984). The film in Nigeria: The context of production. Unpublished Ph.D Thesis, University of Ibadan.

Ekwuazi, H. (1988). The film in national development. A paper presented at the first national workshop on the role of film in national development, University of Jos, Jos.

Ekwuazi, H. (1990). Presenting the shooting script (for film and television). A seminar paper delivered at the Language Arts Department, University of Ibadan, Ibadan.

Eregare, E.A. and Omoera, O.S. (2008). Staging the story: The mise en scène and the Nigerian video film. Iroro: A Journal of Arts 13 (1\&2), 41-49.

Felner, M. (2013). Think theatre. Boston: Pearson Education, Inc. 
Felner, M. and Orenstein C. (2006). The world of theatre: Tradition and innovation. Boston: Pearson Education, Inc..

Foluso, H. (1987). Aesthetics of Moses Olaiyaôs films. Unpublished B.A Project, Department of Theatre Arts, University of Ibadan, Ibadan.

Katz, S.D. (1991). Film directing shot by shot: Visualising from concept to screen. Studio City: Michael Wiese Productions.

Kennedy, T. (1989). Directing video. New York: Knowledge Industry Publications Inc.

LoBrutto, V. (2002). The filmmaker's guide to production design. New York: Allworth Press.

Rabiger, M. (1997). Directing: Film techniques and aesthetics. Newton: Focal Press.

Ralph, S. and Debrix, J.R. (1967). The cinema as art. London: Penguin Books.

Rea, P. W. and Irving D.K. (1995). Producing and directing the short film and video. Boston: Focal Press.

Reisz, K. and Miller, C. (1968). Techniques of film editing. Newton: Focal Press.

Shevtsova, M. and Innes, C. (2009). Directors/Directing: Conversations on theatre. Cambridge: Cambridge University Press.

Sijll, J.V. (2005). Cinematic storytelling: The 100 most powerful film conventions every filmmaker must know. Studio City: Michael Wiese Productions.

Umukoro, M.M. (2002). Drama and theatre in Nigerian schools (A blueprint of educational drama and theatre). Ibadan: Caltop Publications.

Wickham, G. (1992). A history of the theatre. London: Phaidon Press Limited. 